\title{
Logistic Companies in Oman: Role in Boosting Economy, Implementing Eco-Friendly, Technological Logistics for Sustainable Development
}

\author{
Asma Mohammed Abdullah Al Jabri, Zouhaier Slimi, Hind Huwaishal Al Yaqoopi, and Umut Mehme
}

\section{ABSTRACT}

This article focuses on the role of logistic companies in economic growth and how eco-friendly are implementing eco-friendly technology, green logistics, and considering the United Nations Sustainable Development Goals. This research aims to study the logistic sector in Oman and how its practices could be changed into eco-friendly processes to conserve the environment. The study highlights consumption, which encourages the adoption of green practices. Moreover, the research pays attention to the drivers and barriers to green adoption initiatives. The research used quantitative methods in the form of surveys with the help of qualitative evidence from the literature to reach outcomes. The findings vindicate that Oman places great emphasis on the development of logistics services to achieve economic growth. The implementation of green technology allows companies to help the environment and cost savings. Studies are helpful if managers in the business are willing to bring such practices into their business. There is a need to align sustainable development and logistics operations to support the SDGs in their CSR initiative. The shift usually takes a long time, but the initiative must be taken, and governmental bodies must support the greening of the logistic industry. Research findings reasonably advocate the share of the logistic industry in economic growth, so investments in this sector would only lead to better trade and more earnings whilst conforming to the customers' demands. The study faces some limitations, including a limitation and superficiality in the information presented in the green logistics aspect. The COVID-19 outbreak made it challenging to reach the target people of the survey.

Keywords: Economy, Environment, Green technology, Goals, Logistics, Sustainability.

\section{INTRODUCTION}

Logistics is considered one of the three most significant industries with microbiology and gene technology in the twenty-first century. Now that there are improved and advanced methods of conducting businesses efficiently, logistics have become an essential part of the production and trade sector. Logistic activities facilitate the process of manufacturing companies by transporting the raw materials to be processed then delivering them to the end consumers. Logistic operations [1] include fundamental tasks like transportation of goods, warehousing, handling, and inventory management customer-specific services. All these services have created value for the logistic industry, and thus they have a high level of share of services in many countries. [2] The growth in this industry has created employment opportunities for transporters, warehouse owners and freight employees. As a result of globalisation, nations have increased their logistic capacities to cater to international trade. The logistic industry has created a competitive advantage amongst the nations who invest in this field and facilitated their distribution processes and marketing
Submitted : September 30, 2021

Published : October 22, 2021

ISSN: 2507-1076

DOI: $10.24018 /$ ejbmr.2021.6.5.1127

Asma Mohammed Abdullah Al Jabri* BA student the Logistics and Transport Management Department, International Maritime College Oman, Sohar, Oman.

(e-mail: 003986-16@imco.edu.om)

Zouhaier Slimi

Lecturer Foundation Department, International Maritime College Oman, Sohar, Oman.

(e-mail: Zouhaier@imco.edu.om) Hind Huwaishal Al Yaqoopi

Assistant Lecturer-Logistics Management, International Maritime College Oman, Sohar, Oman.

(e-mail: Hind@imco.edu.om)

Umut Mehmet

Lecturer- Logistics Management, International Maritime College Oman, Sohar, Oman.

(e-mail: Umut.mehmet@imco.edu.om)

*Corresponding Author strategies with fast deliveries and efficacy. [3] Companies gain an advantage in cost and efficiency by integrating logistic activities in their business. Logistics has become a crucial and indispensable element to trade in times of growth and development [4]. Logistics is vital to the distribution industry and has made distribution fast and efficient. Indeed, according to the Freight Transport Association (FTA) [5], in 2014, 139 billion tons of cargo were transported by HGV. Companies are getting stronger by investing in transportation and logistics. Therefore, logistics determine how quickly goods can be delivered to customers and gain a competitive advantage over those who do not work for them [6].

The technology sector is also benefitting from the increase in logistics. As operations in businesses are digitalised worldwide, logistic companies also integrate digital strategy into their supply operations. They continuously improve their methods and provide better services by tracking orders and vehicles to facilitate visibility. The enhanced visibility by deploying technology in logistics has helped optimise transportation of goods in less time with lower costs, thus becoming an essential factor in benefitting the economy [7]. Organisations are now moving towards green logistics and 
managing organisational practices in the best interest of environmental concerns. Industries produce much waste, and the need to reduce the pollution in the environment, greening strategy in supply chain management is being adopted [8]. It is observed that logistic operations have contributed to raising the pollution levels that are hazardous for the environment and bad for the economy. Green logistics, therefore, refer to reforming the logistic operations to save the environment and designing, sourcing and producing and transporting materials and goods that pose no threat to the environment. It also involves considering the internal and external factors involved in logistics operation, thus controlling them in environmental concern [9]. As environmental health is declining, businesses are showing more interest in adapting to environmentally friendly strategies and producing products that help keep the environment safe. Organisations are shifting towards ecological systems by carefully producing products reducing the harmful impacts to the environment and creating a competitive advantage for themselves [10]. Since the 1990s, the emission of CO2 gas has drastically increased, and the freight transportation sector contributes to the risk of pollution. Thus, the need for initiating green transportation arises [11]. It has increased by $71 \%$ in 2016 and is anticipated to increase $50 \%$ more by 2050 . In the early years of 2000, standards for purchasing goods were revised by regulating authorities. The use of disposable items was greatly discouraged because they were not eco-friendly replaced by-products properly recycled with maximum durability [11]. Organisations are attempting to become socially responsible. Green warehousing has increased quickly over the years, and organisations are promoting green practices. As inventory management and warehousing have become crucial in logistics, organisations are focused on minimising and controlling carbon consumption and environmental pollution [12]. This research aims to determine the logistics industry's role in economic growth as not many studies have investigated its importance and relevance [13]. Moreover, the implementation of green technologies to generate green logistics. This research would pay attention to the sustainability goals adopted by all United Nations Member States in 2015.

\section{A. Research Objective}

This research aims to study the logistic sector in Oman and how its practices could be changed into eco-friendly processes to help save and conserve the environment. The rising concern of the stakeholders all around the globe to conserve the resources and have less environmental impact becomes of crucial problem, which is one of the goals of sustainable development. So, this study will determine the role of the logistic industry in economic growth and how the processes could be made green by employing green technologies instead of the traditional excessive energyconsuming ones and how the distribution processes will be made green adopting green practices. The variables studied in this research include the impact of transportation and communication representative of the logistic industry on the per capita income. Also, we will examine the drivers that attract the attention of stakeholders to adopt green technologies and invest in them. Thirdly and lastly, we will study the variables such as velocity and emission of $\mathrm{CO}_{2}$ that have a severe environmental impact and ways it can be reduced to make the distribution processes green [14]. The various steps involved in this research will include a complete literature review of all these variables and a study suggesting associations between the variables. After that, research would be conducted by qualitative and quantitative methods in surveys that will help build our case and answer our research questions.

\section{B. Scope of Research}

This research aims to look at how the logistics industry contributes to economic growth. Also, significant concern about environmental impact doing the practices green by adopting green technologies and making logistics green is studied. This research is supposed to make predictions about the logistic sector in Oman. Because much data is not available in Oman, just the information is available. We will resort to already existing models that will help bring this change [24]. To answer the three research questions, we have referred to different studies, and the time frame is different for each one. Data is collected and studied to study the role of the logistic industry in economic growth. For the implementation of green technologies, a one-time survey has been conducted, and for the implementation of the green logistic sector in Oman, we have conformed to the mathematical models applied in the case studies that will help us understand how the practices could be turned green in logistics. A qualitative study is conducted on economic growth due to the logistic sector, and evidence is found from the literature that supports our reservations about the topic. This study is conducted in the 34 OECD countries, and we believe it represents economic growth for other countries like Oman. The international survey being conducted by experts will help us understand how significant an impact of green technology is evident and how it could be employed and help save costs and the environment at the same time [25]. The international survey is applicable as a role model for all the countries; therefore, Oman could be benefitted from the study conducted in more than one country, yielding similar results. With the help of a case study, the green logistic study will reflect on methods adapted to mark environmental concerns during the transportation and logistics business. This green model could be adopted globally and is beneficial for the community of Oman if adopted and implemented.

\section{Significant of the Research}

As many studies relating to the logistic sector are conducted in a limited number of countries, this research in Oman will help the logistic industry revamp its processes. With the growth of this sector, they could begin to contribute to the environment as well. This study will advocate the advantages and necessity of implementing green technologies to take up these practices in their business, contribute to their social responsibility, and address customers' concerns while making their best services. With the growing concern for the business activities' environmental impact, the stakeholders are concerned about shifting to green practices. This study will help the managers understand the shift from traditional methods and help them work on their processes to improve their businesses and environment at the same time. 


\section{LITERATURE REVIEW}

Logistics companies perform the functions like planning, designing, and implementing the transportation of materials and warehousing, which supports inventory management and product distribution functions. Businesses recognise logistics as a competitive edge over their competitors [15]. When globalisation started, logistics gained value, and companies crossed borders to tap into new markets with better production efficiencies and technological advances. Manufacturers are working on their supply chain competitiveness and outsourcing logistics services, making the logistics sector more valuable. Logistics is vital to the trade and manufacturing sector and contributes to the economy [16]. With the growth in the logistic industry, the importance of technology has increased. Information technology (IT) offers a great future for the logistic sector by enhancing its efficiency and flexibility. Therefore it is determined as the critical factor in future logistic systems [17]. The high cost and revolutionary technology that can revitalise logistics processes include robotics, system, and storage automation.

Furthermore, Medium cost technologies include barcodes, optical scanners, and hardware applications. Low-costs include software systems that can facilitate inventory control and warehousing. Information and communication technology has helped automate most of the functions. It allows activities to perform faster and facilitate distribution operations [18], resulting in greater logistics efficiency. Transportation usually happens on long routes and tracking, and tracing have become essential to tracking shipments. Information and communication technology applications have made tracking shipments and their condition easier, facilitating claims processing and settlements [19].

\section{A. Background of Green Technology}

Businesses are now moving towards sustainable technology, which is "Green technology" with a green insight. Green usually refers to nature, but it considers the long-lasting impact of innovation on the environment in green technology. Some researchers, such as [20], explain green logistics to balance environmental, social, and economic components by finding methods to reduce operations costs. Green logistics includes the perspective of ecological performance while measuring the business activities and making it efficient with the help of elements from supply chain management [20]. According to [21], "The main elements of the modern concept of green logistics are time and costs, which interact with each other in the environment to produce the products in an optimum manner, distributing the products at the lowest cost and in the shortest possible time while minimising the rate of product spoilage. waste and work to recycle waste to achieve optimal use." [21].

\section{B. Sustainable Development Goals}

The 2030 Agenda for Sustainable Development, adopted by all UN member states in 2015, provides a standard blueprint for peace and prosperity for people and planet Earth, now and for the future. At their core lie the 17 Sustainable Development Goals (SDGs), an urgent call for action by all countries - developed and developing - in a global partnership. They recognise that ending poverty and other deprivations must go hand in hand with strategies that improve health and education, reduce inequality, and stimulate economic growth - all while tackling climate change and working to conserve our oceans and forests. Provides technical support and capacity building for the Sustainable Development Goals and related thematic issues, including water, energy, climate, oceans, urbanisation, transport, science and technology [22]. Indeed, most of the elements of the 2030 Agenda will only be realised with a sustainable transport sector supporting world trade and facilitating the global economy. So, for that, logistics and supply chain need to concentrate and indicate these sustainability goals. There are 17 SDGs shown in Fig. 1.

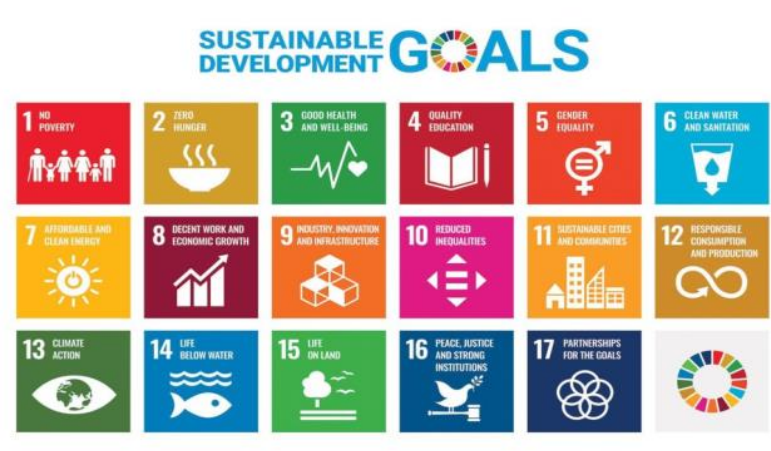

Fig. 1. Sustainable development goals [22].

\section{Role of Logistic Companies in Economic Growth}

Logistics have a close relation with economics; therefore, it created the concept of economics of logistics. Economics of logistics [23] studies the methods that will help perform operations at lower costs, yielding greater return and maximising profits while fulfilling the customers' demands. Good management plays an essential role in achieving this efficiency level. In other words, logistics focuses on improving productivity, employment and growth that will directly contribute to a better economy while making profits and more significant returns [24]. Investigated the impact of logistics on the economy in OECD countries, and it comprehended those developments in the logistic sector are determinants of economic growth. The transportation infrastructure plays a vital role in national economic activities. The development of commerce is directly related to cutting costs of transportation and increasing the movement of goods. More effective the logistic processes, more the improvement and competition among corporations on the microscale and national economies on the macro scale.

\section{The Implementation of Green Technology}

Implementing green technology is necessary as it reduces the emission of GHGs compared to standard cars, thus leading to a sustainable environment [6]. Technologies significantly impact our society and territory, but their advancement has helped globalisation and formed an advanced global economy [20]. Undoubtedly, green technology is necessary for the green environment, but it faces immense challenges that make the goals unattainable. The challenges include marketing challenges, economies of scale, financing problems, and regulatory and technical 
difficulties [11]. New eco-friendly technologies are aimed at increasing the growth rate with minimal costs and reducing damage. However, it is deduced that green technologies are costlier than old ones, and companies are hesitant to adopt such practices due to financial stress. Assuming and applying green technology has some constraints caused by several other barriers, which may be customary, such as the lack of an appropriate regulatory framework; or technical, economic, political, cultural, and legal. Regulations regarding green technology vary from country to country, and it is difficult for businesses to identify, meet and manage[25]. Complex rules and regulations of entry into the green technology global markets make it difficult for medium-sized and small enterprises to penetrate the market via green technologies [1].

\section{E. Using Eco-friendly Technologies to Implement Green Logistics Sectors}

To achieve the expected outcomes from the green practices in the logistics industry, all entities like industry, society and government must work together to bring this change. Technology is a major driving force to achieve the benefits of the environment [26]. However, when all industries are open to accepting the concept of green technology, it becomes difficult for small-sized companies to adopt it because this area requires significant investments, and the technology is costly. Thus, researchers contemplate the cost-benefit analysis of this technology that will help attain business outcomes and environmental innovation [27]. Green technology is implemented in Malaysian society, and firms have provided incentives to develop this initiative. The number of companies implementing green practices has increased, but they contribute to the economy positively and promote sustainable development [28]. One factor that affects the implementation of green technology is the user's behaviour towards such innovation and its impact on society [36]. Therefore, market focus has become one major factor influencing the performance of greener products [24]. Green logistics aims to reduce logistics costs and increase profits to maintain sustainable development; in other words, it affects the financial statements by considering the cost element, the cost components, and their direct impact on corporate profitability. It is the social responsibility of individuals, businesses, and the government to save the environment and integrate their activities, such that the implementation of a green economy can achieve through green logistics [28]. Accordingly, companies must deal with internal and external factors in green logistics that impact them significantly [29]. [35] defines the internal and external driving forces regarding the implementation of green logistics.

Internal factors include the ability to enhance risk management due to potential organisational factors (organisational support, human resources efficiency, business size), Technical factors (relative benefit, compatibility, complexity), Environmental factors (customer pressure, regulatory pressure, government support, environmental uncertainty). Supply chain interruptions and cooperation with suppliers to identify alternative products and devices reduce the effect on the environment. The external ones include customers, investors and non-governmental organisations [30]. [34] analyse the factors that are essential to the introduction of green supply chain management (GSCM) activities and extract 20 four-dimensional critical factors (supplier management, commodity recycling, participation of organisations and life cycle management) [31]. Present 11 driving forces (and their interactions) analysed using Interpretive Structural Modeling (ISM). The research findings indicate that government regulations, legislation, and reverse logistics are essential driving factors for product designers and manufacturers to reduce and eradicate the environmental effect of products. The private sector considered reducing the environmental impacts, developing strategies and taking actions to deal with it by incorporating green logistics to save the resources and the institution [32].

\section{Methodology}

\section{A. Research Framework/Design}

To study the role of the logistics industry in the economic growth of Oman, the researcher has referred to similar research conducted on the same prospect in 34 OECD countries. It includes Austria, Belgium, Canada, Denmark, France, Germany, Greece, Iceland, Luxembourg, Netherlands, Norway, Portugal, Spain, Sweden, Turkey, Ireland, United Kingdom, Italy, USA, Japan, Finland, Australia, New Zealand, Mexico, Czech Republic, Estonia, South Korea, Slovakia, Slovenia, Chile, Israel, Hungary, Poland [6]. The researcher believes this data represents the contribution of the logistic industry to the economic growth of any country. Data from 2000-2014 was collected for this research, and an unbalanced panel data analysis was conducted. Investigations of the logistic industry's role taken variables relating to it, such as transportation and communication, represent this industry. Statistical data under study in this research were acquired from World Bank websites. Two different econometric models were constructed with the help of a dependent variable, i.e., per capita GDP. Public expenditures, fixed capital investments, employment and human capital have taken control variables in both models. The second part of our research investigates the implementation of green technologies in Oman. The researcher refers to the international survey conducted by experts on green building technologies to help us understand the implementation factors.

After a thorough literature review, the one aspect that concerns our study is the reduced environmental impact that drives the concept of green building technology. A questionnaire survey method was conducted to find the main drivers for implementing green building technologies [18]. The questionnaire emphasised finding out the drivers for green building technology, barriers to adoption, and strategies for promoting its adoption. A pilot test was conducted to exclude any unnecessary factors from the questionnaire and then mailed to experts to have their professional opinion on the drivers of green building technologies. Likert scale with a range from strongly agree to disagree opted for the measure firmly. To evaluate the implementation of the green logistics sector in Oman, tried to understand the practices that would optimise the business processes while having minimal environmental impacts. The researcher resorted to developing and implementing green logistics in the batch industry to make the distribution channels green. The primary 
focus is on the reduction of $\mathrm{CO}_{2}$ emissions by mobile sources that have environmental consequences. Used to calculate emissions, fuel, and mileage-based methodology. Therefore, stochastic travel velocities and arrival times are estimated. A mathematical model was created with its application in two case studies relating to the batch processing industry [33].

The research design is shown in Fig. 2 below.

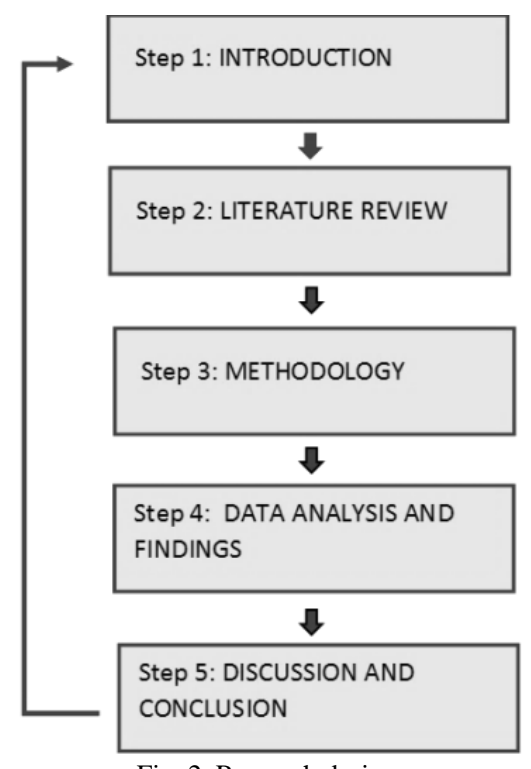

Fig. 2. Research design.

Step1: Explain the basic knowledge about the research problem, the objectives of the research, and the reason behind conducting this research.

Step 2: Focuses on the importance of reviewing the literature for the research conducted; this will give the reader full knowledge and basic ideas about the study.

Step 3: It describes research methods for collecting data, mainly to analyse primary objectives, research methodologies, and designs.

Step 4: Aggregate data analysis and findings gathered from methods used.

Step 5: Summarise the objectives, main contributions and highlight future recommendations for research and recommended studies.

\section{B. Limitation of the Research}

The study of 'conduct study of the role of Logistic companies in economic growth while implementing ecofriendly technologies and a green logistics sector in Oman' faces some limitations. The researcher's first limit, the data collected for the research of the role of the logistic industry in economic growth is from the general applicability of the study conducted in 43 OECD countries, it is difficult to infer that the same results will be visible in Oman context. The research can perform with the same county's logistic industry data within a limited period for better results. Moreover, there is a limitation and superficiality in the information presented in this aspect [47]. The second limit that has been a struggle with is the COVID-19 outbreak. Because of the health problem, frequently, Omani authorities acting to curfew all around the Sultanate make it challenging to reach the target people of the survey or interviews. The third is related to a methodological limitation, which is the insufficient sample size for statistical measurement. It is essential to collect a sufficient sample size to infer a valid research result when conducting a study. If the sample size is minimal, it will be challenging to determine essential relationships from the data. There is a concern that the sample is insufficient. In anticipation, the researcher chooses an appropriate sample size before using scientific calculation tools [37].

\section{Data Collection}

In scientific research, there are two methodologies for quantitative and qualitative research. According to [11], researchers use different methodologies that fit their goal and inquiry into the research. The data collection used in the paper is qualitative (literature review) and quantitative (survey) methods, as many studies have not been conducted in the logistics sector. These methods help suit the research's purpose and answer research questions, including investigating green technology implementation and green logistics in Oman. The data were collected to answer three research questions, which are "The role of the logistics sector in economic growth", "Implementation of green technologies in Oman", and "How to link environmentally friendly technologies to implement green logistics sectors in Oman" [20].

\section{Survey Questionnaire}

Questionnaires support our quest to answer the research questions. The questions were thoughtfully created to answer our research questions. Some questions are open-ended, and some are provided with multiple choices or the level of agreement or disagreement with the statements. As the research needs responses from different logistics users, Questionnaires are the appropriate and quick way to collect enough responses. The set of questions is designed to reach research objectives and outcomes properly. It will be sent to different logistic users through email and phone [14].

\section{E. Population and Sample Size}

The sample size is the total number of completed survey responses received. It is called a sample because it represents only a group of people (or target population) whose behaviour or opinions are of interest. The selection should represent the population to ensure that the researcher can generalise the results from the research sample as a whole population. In this study, the researcher surveyed people who have experience in the logistics field or are familiar with green technology and green logistics. The researcher will obtain samples by sending the questionnaires through email and mobile phone [7].

\section{RESUlTS AND DISCUSSION}

The primary research question is: What are the roles of Logistics companies in the economic growth of green logistics sectors in Oman while implementing eco-friendly technologies? The research sought to respond to this essential question by answering the following survey questions.

This pie chart (Fig. 3) is about the participants' thoughts about the logistics industry's contributions to Oman's economic growth. $53 \%$ of participants strongly agree, $16 \%$ agreed, and $20 \%$ strongly disagree. Balance is neutral and disagreed participants. 


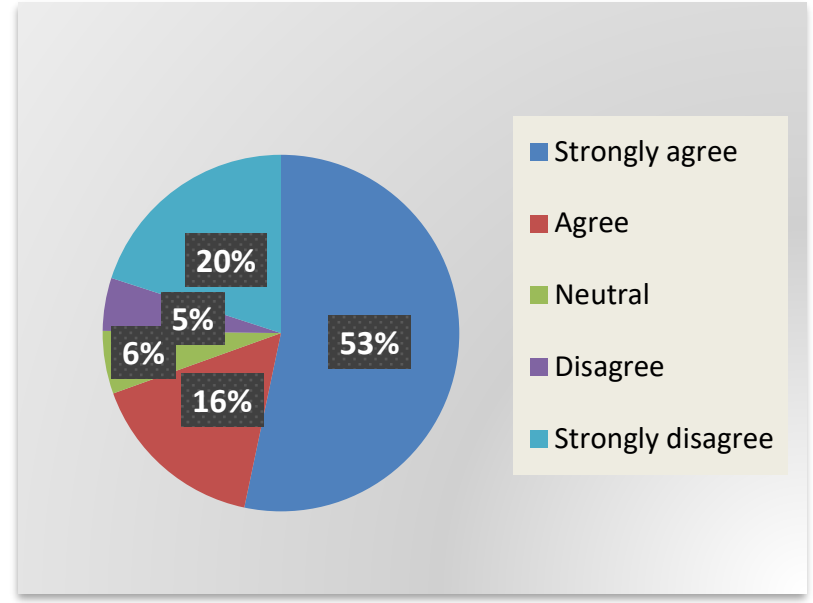

Fig. 3. Logistics industry contribution to the economy of Oman.

This chart (Fig. 4) shows the participant thought about the logistics role in economic growth represents a high carbon footprint. Here $33 \%$ of people strongly agreed, $30 \%$ of people agreed and, $23 \%$ people disagreed, and $6 \%$ were neutral with the given statement.

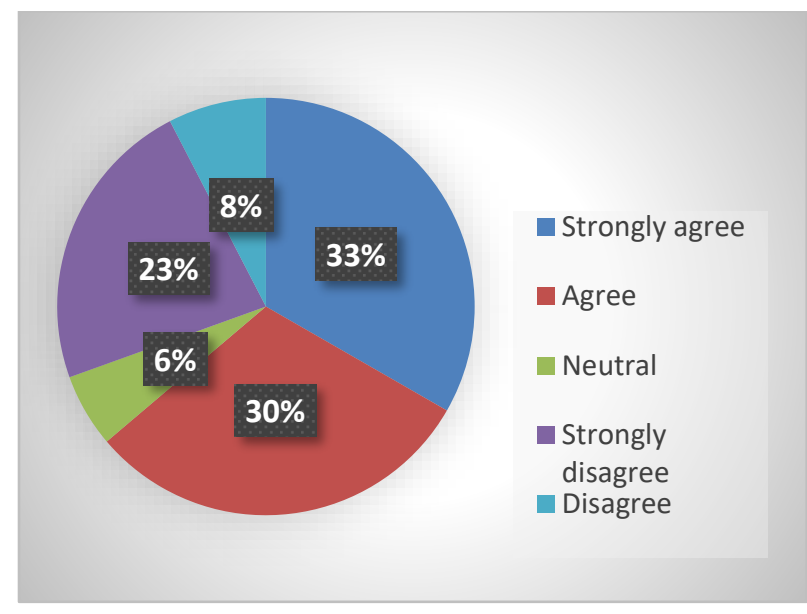

Fig. 4. Logistics represents an area with a high carbon footprint.

The logistics process will promote environmental improvements, and sustainability questions are illustrated in this pie chart. $32 \%$ of people strongly agree, $30 \%$ agreed, $24 \%$ strongly disagreed, and $3 \%$ disagreed with the above statement, as shown below in Fig. 5.

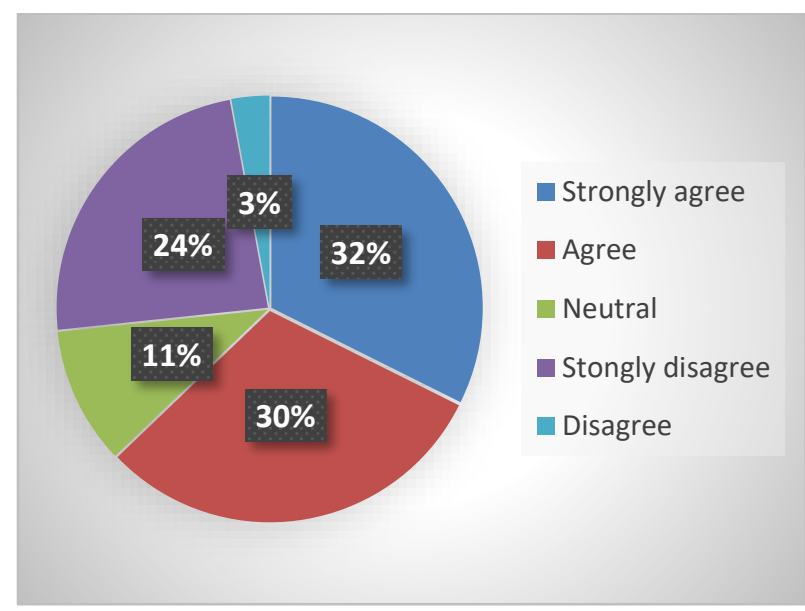

Fig. 5. Technology contribution in the logistics process will promote environmental improvement and sustainability.
This chart (Fig. 6) talks about the green technologies that help logistics companies be eco-friendly, $15 \%$ of people agreed on fleet management, $11 \%$ for route optimisation, $9 \%$ on intelligent logistics and $10 \%$ for cargo delivery drones, $11.4 \%$ on renewable energy sources and $29 \%$ agreed on using all mentioned technologies.

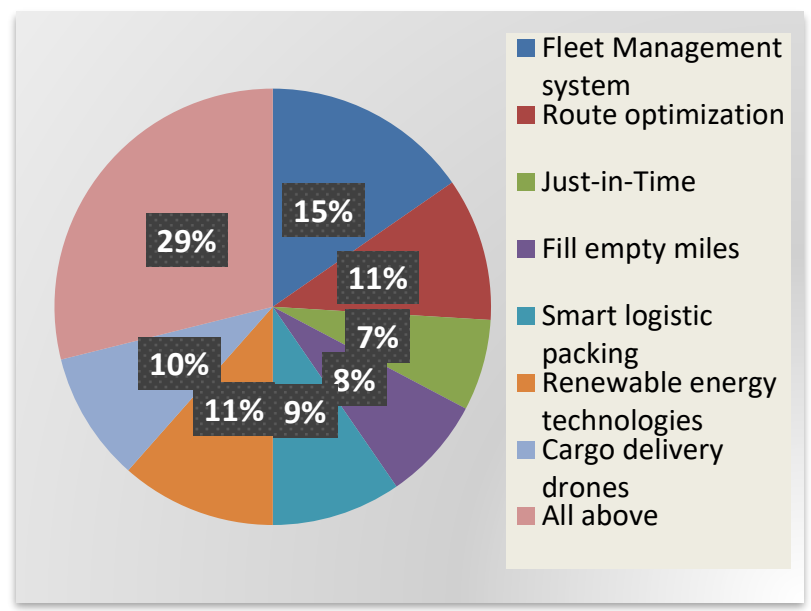

Fig. 6. Environmentally friendly technologies.

The bar chart (Fig. 7) illustrated the Oman logistics industries green adoption barriers. Different types of barriers are listed in this chart, and the barrier level is displayed in different coloured bars. The highest number of people agreed that all mentioned barriers are not considered a barrier, where the second-highest number goes to somewhat barrier, where people believe these barriers could generate issues on implementing green logistics. Lack of demand for green construction, people, believes that green building is not essential, and inadequate quality of human resources are the top three were rated as not representing a barrier with several responses 59, 54 and 53, respectively.

Responses of 35 show that the absence of pressure and incentives from a government is considered a barrier that has little impact in adopting eco-friendly applications, where 33 responses accept that the insufficient information of green adoption becomes somewhat a barrier. Resistance to technology advancement adoption and Poor quality of human resources are the main moderate barriers. The absence of pressure and incentives from the government and lack of initiative by governmental/professional bodies are two barriers that people significantly believe struggles with the green implementation in Oman, where it needs more concentration from the government.

The bar chart (Fig. 8) illustrates the ratings of significant drivers of green logistics initiatives. Each column shows the rate for every motive with the number of people responding. 34 of People see the adoption of green logistics as the best way to protect the environment, which rates as a moderate driver. 28 of responses shows it is a fragile initiative, while 18 agreed it is a powerful way to encourage green technology implementation. The second initiative helps the firms decrease energy and logistics costs and improve their financial and operational performance where 26 responses see a week and 25 a moderate, and 7 people agreed on a powerful way. Competition considers as a driver of green adoption for many countries and firms 29 people show it is a 
feeble way to support green technology, where 28 moderate and 20 responses believe it as vital. The government has many incentives to encourage green logistics 31 responses rate a very weak and 25 accept as a moderate, which can positively impact green buildings. It shows that the company cares about society and the environment 27 responses rate fragile were 14 robust. Green logistics are a safe way to avoid trespassing on laws and regulations 30 of people rate moderate driver while lower 13 responses an initiative is vital.

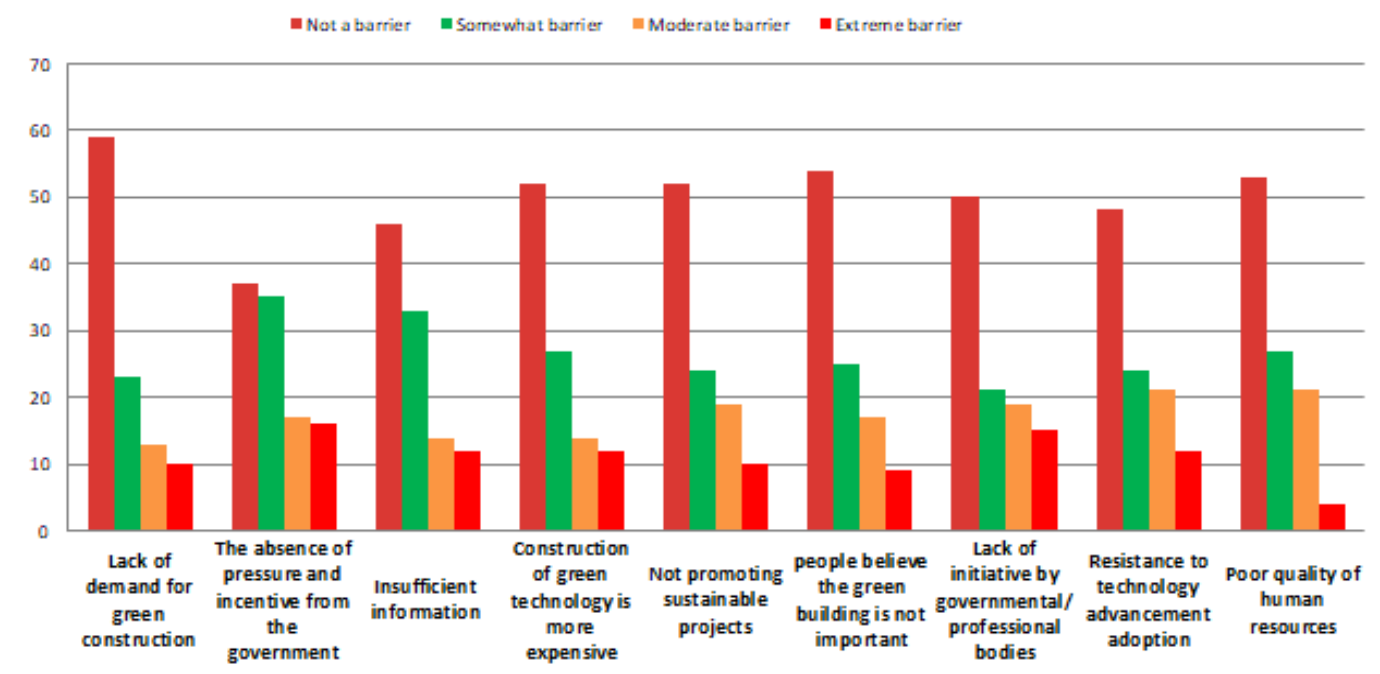

Fig. 7. Barriers to green adoption.

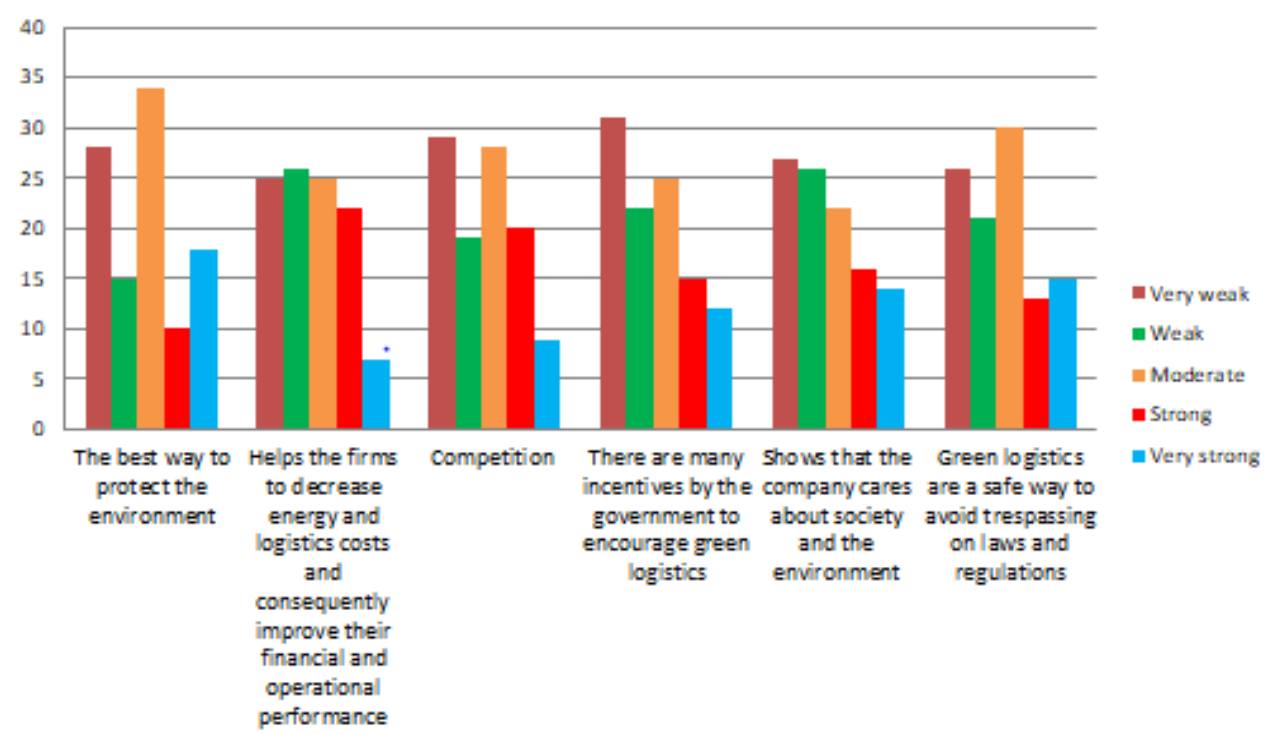

Fig. 8. Drivers of green logistics initiatives.

\section{DISCUSSION}

The oil industry is the backbone of Oman's economic growth. The recent fluctuations in the oil sector led to an undesirable impact on the country's economic development. The Sultanate of Oman emphasises diversifying the economy by developing the non-oil sectors to avoid uncertainty in the oil sector. The non-oil sectors include the significant need for growth in the transportation and logistics fields in Oman. Therefore, Oman places great emphasis on the development of logistics services to achieve economic growth, which is shown by competing with the major players in the industry, which made it a major logistics centre in the Middle East. The continuous growth in international trade makes supply chains more complex. Logistics networks are interconnected, more economic centres across the oceans and continents, Change consumer preferences and new manufacturing requirements.

All have resulted in more frequent and smaller charging shipments and, consequently, to fewer full containers, more empty runs and more speed demand, the Carriage of goods whether by air, land or sea is still depending on fuel, there is still a long way to go from being able to switch to cleaner energy sources, leading to higher carbon emissions. The implementation of green technology allows companies to help the environment and cost savings. Environmental technology includes sustainable or environmental technology and covers an ever-evolving combination of methods, practices, and materials, from energy generation to non-toxic cleaning products. It considers the long- and short-term impact of something on the environment. Green technology is environmentally friendly because it includes energy efficiency, health and safety concerns, recycling, renewable resources, and many other things. However, all technologies contribute to reducing $\mathrm{CO}_{2}$ emissions but in different ways and levels. The effectiveness depends on the company efficiency and capability in using the right technology in the right place in the logistics process. Oman logistics industries face different green adoption barriers. In general, for all the 
barriers mentioned, it is agreed that they constitute a barrier even if a high number consider not a barrier, the remaining responses agreed on a barrier. Whether it is strong or slightly weak, or moderate or somewhat barrier, these barriers can be divided into four categories, Economic barrier which includes, construction of green technology is more expensive, Capacity / Professional barriers, contain Lack of demand for green construction, Not promoting sustainable projects and Poor quality of human resources. The societal barriers include people belief the green building is not essential, a Lack of initiative by governmental/professional bodies and the absence of pressure and incentive from the government. The technological barriers include the resistance to technology advancement adoption. The study showed that the driving factors fall within the "medium" level, except the lowest, within the "low" category. This indicates that, in general, any current actions to advance the concept of green building in Oman may not have a significant impact on the industry, but the driving forces that should stimulate green growth are still at a low to medium level.

\section{SDGS ENGAGEMENT}

Logistics companies need to support the SDGs as part of their CSR initiative by identifying medium and long-term opportunities and risk factors to enhance alignment between sustainable development and logistics operations.

The United Nations has declared 17 Sustainable Development Goals to address economic, social, and environmental issues. Companies should review the alignment between these goals and corporate-wide sustainability strategies and integrate them into their medium and long-term plans. Therefore, they need to Focus on areas that directly impact or are expected to impact achieving goals positively. The goals that are directly connected with logistics activities are.

- Goal (6): Clearwater and sanitation

Ensure availability and sustainable management of water and sanitation for all.

- Goal (7): Affordable and transparent energy

Ensuring access to sustainable, reliable, and affordable energy sources for all.

- Goal (8): Decent work and economic growth

Promote sustained, inclusive, and sustainable economic growth, full and productive employment, and decent work for all.

- Goal (12): Responsible consumption and production

Ensuring sustainable consumption and production patterns Goal (14): life below water.

Converse and sustainably use the oceans, seas, and marine resources for sustainable development. Ocean acidification continues to threaten the marine environment and ecosystem services. The work of IMO Relates to most, if not all, but Goal 14 of the Sustainable Development Goals, in terms of environment conventions, implementation and Enforcement of significant agreements and regulations approved by IMO member states actively treat marine pollution mainly from the sea Resources. Despite this, the intense drop in human activity caused by COVID-19 may be an opportunity for oceans to recover [22].

\section{CONCLUSION AND RECOMMENDATION}

\section{A. Conclusion}

This study aimed to determine the relationship between the logistic industry and economic growth and how green technology and green logistics could realise sustainability goals. The literature review significantly advocates the importance of greening business practices, and as logistics has become an essential part of nearly every business, we have studied its positive impact on economic growth. We studied models that corroborated transportation and communication as the representative of the logistic industry and analysed their impact on the per capita income. According to our findings, the logistic industry has a positive and significant relation with growth in per capita income, and thus we recommend that more investments be made in this sector to boost the economy. We also studied the drivers that brought about the implementation of green technologies, and among them, the major one was the concern of stakeholders for the environment. The Greening of technology does not only save the environment but also help reduce business costs[30].

Moreover, the greening of the logistic sector was studied in a batch process industry, and we conclude that if we control the delivery velocities and emission from vehicles, we can reduce the environmental impact. Also, the optimal delivery and distribution systems help reduce business costs. This study is profoundly helpful in its application in the Oman society context and will pave the way for more researchers to add to this study and better understand the impact of the logistic industry and conservation of the environment.

\section{B. Recommendation}

This detailed research on the role of the logistic industry in economic growth, and the implementation of green technologies and green logistics, call for applicability in the logistic sector of Oman. Studies are helpful if managers in the business are willing to bring such practices into their business. The shift usually takes a long time, but the initiative must be taken, and governmental bodies must support the greening of the logistic industry and play its part in leading society to a positive change. Research findings reasonably advocate the share of the logistic industry in economic growth, so investments in this sector would only lead to better trade and more earnings whilst conforming to the customers' demands.

\section{Renewable Energy Development}

Natural resources such as sun and wind must be brought into use while operating technologies so that there is less emission of harmful gases and businesses can reduce costs. Solar intensity is high in Oman. There is also great potential for coastal wind energy in the coastal areas in the southern part of Oman and the mountains north of Salalah. Further studies should be conducted to investigate offshore winds, geothermal heat, tides, and waves. Financial support for studies that lead to the exploration of renewable energy in Oman and its applications.

\section{Drones' Delivery Services}

Drones are gaining importance in the distribution and transportation of goods, especially with the emergence of e- 
commerce and delivery requirements. However, it is limited by hardware limitations such as battery life, payload capacity, and flight stability in windy conditions. Furthermore, regulatory, and legislative aspects related to privacy and safety issues remain an obstacle in Oman. This market segment of drones represents a substantial long-term business opportunity but requires diverse stakeholders to collaborate on pilot projects and community initiatives. There are many initiatives started on experiment drones in Oman. One corporation between The Technology team in Oman Logistics Centre (OLC) and Asyad experimented with parcel delivery and inventory using drones.

The first experience saw parcels delivered in Nizwa and Muscat. The Nizwa drone transported a package weighing about 1.5 kilograms, approximately three kilometres just over four minutes. The Muscat drone successfully transported a package weighing about $5 \mathrm{~kg}$ in less than four and a half minutes before returning on a round trip of more than $3 \mathrm{~km}$. OLC's drone inventory trials were also very successful, producing the first automated inventory in warehouses in the Sultanate. The trial, monitored in partnership with Al Safa Logistics and attended by representatives from eight other prominent Omani logistics companies, used specialised indoor drones to track cargo pallets in real-time [49].

\section{E. Implementing Eco-friendly Practices}

Green supply chain management practices are an exciting area of research and practice. More tremendous external pressures from various stakeholders and organisations force companies to effectively implement GSCM practices that ultimately improve their environmental and economic performance. GSCM incorporates a wide range of practices throughout operations and the larger supply chain. Green logistics practices should be advocated to ensure the sustainability of the current generation and the future generation. This is because the operations of the logistics industry are the most widely known for affecting the natural environment in the most negative way.

Recommended to Starting with Practices Included:

1. green packaging;

2. green purchase;

3. Environmental Performance Practice Audit (according to Sustainable Development objectives);

4. Selection of partners and assessment of their environmental performance;

5. Conducting environmental management knowledge training for employees;

6. Educate employees, Friends, Colleagues, and Families on the Global Goals;

7. Urging companies to act;

8. There are many ways a company can begin to support global goals, through launching an international corporate volunteer program or simply helping promote them through the media;

9. Recycling containers and other packaging materials ;

10. Reduce the use of transport packaging;

11. Transportation waste recycling control;

12. The use of recyclable packaging materials and logistic containers;

13. Improve transportation methods;

14. Choosing the proper mode of transportation;
15. Improved transmission load distribution;

16. Monitor the mileage of the trucks;

17. Take advantage of integrated transportation.

\section{ACKNOWLEDGEMENT}

I thank my instructors, who were more than generous with their expertise and precious time. A special thanks to my genuine and honest supervisor Ms Hind Huwaishal Al Yaqoopi, for her encouragement and support until I finished the research. I would also like to extend my gratitude to the second reader Mr Umut. Also, I would like to acknowledge and thank my school division for allowing me to conduct my research and providing any assistance requested. Finally, I would like to thank all teachers and administrators in our school division that assisted me with this project. Their excitement and willingness to provide feedback made the completion of this research an enjoyable experience.

\section{REFERENCES}

[1] D. Aboginije, Ademilade \& Aigbavboa, Clinton \& Aghimien, The application of Green Technology. 2019.

[2] S. Aithal, S. Aithal, and P. S. Aithal, Opportunities \& Challenges for Green Technology in 21st Century Opportunities \&amp; Challenges for Green Technologies in 21 st Century, vol. 73661, no. September. 2016.

[3] R. Bhatnagar, A. S. Sohal, and R. Millen, "Third-party logistics services: A Singapore perspective," Int. J. Phys. Distrib. Logistics. Manag., vol. 29, no. 9, pp. 569-587, 1999, DOI: 10.1108/09600039910287529.

[4] O. Journal, "The Report: Oman 2017," 2017.

[5] Rosario M. Vasco Reis, "Intermodal Freight Transportation," 2019.

[6] Biac OECD, Technology development and deployment to address green growth challenges, vol. 33, no. October. 2010.

[7] S. Bin and S. Chaoyuan, The correlativity analysis between logistics industry and national economy development, no. 1. 2005.

[8] D. Bovet, "Logistics strategies for Europe in the nineties," Plan. Rev., vol. 19, no. 4, pp. 12-48, 1991, DOI: 10.1108/eb054328.

[9] D. J. Bowersox, DJ, and Closs, Logistical Management-The integrated supply chain process. New York: McGraw-Hill, 1996.

[10] Anthony W. Alan McKinnon, Michael Browne, "Green Logistics: Improving the Environmental Sustainability," 2012.

[11] A. Bryman, "The Debate about Quantitative and Qualitative Research: A Question of Method or Epistemology?," Soc. Surv., vol. I, pp. 13-29, 2002.

[12] Niaz W. Walid Besbes, Diala Dhouib, "Solving Transport Problems: Towards Green Logistics," 2020.

[13] T. Carrillo-Hermosilla, J., Del Río, P. and Könnölä, "Diversity of ecoinnovations: reflections from selected case studies," J. Clean. Prod., vol. 18(10), pp. 1073-1083, 2010.

[14] C. W. Hu, A. H., \& Hsu, "No TitleCritical factors for implementing green supply chain management practice: an empirical study of electrical and electronics industries in Taiwan.," Manag. Res. Rev., vol. 33(6), pp. 586-608, 2010.

[15] W. Kwasnicki, "Logistics growth of the global economy and competitiveness of nations. Technological Forecasting and Social Change.," vol. 80(1), pp. 50-76, 2013.

[16] L. Kleindorfer, P.R., Singhal, K. \& Van Wassenhove, "Sustainable Operations Management," Prod. Oper. Manag., vol. 14(2), pp. 482 492,2005

[17] T. A. Lancioni, R.A, Smith, M.F \& Oliva, "The role of the internet in supply chain management.," Ind. Mark. Manag., vol. 29, pp. 45-56, 2000.

[18] N. M. El-Berishy, N, Scholz-Reiter, "Development and implementation of a green logistics-oriented framework for batch process industries: two case studies," Logist. Res., vol. 9(1), pp. 1-10, 2016.

[19] L. Markley, M.J., \& Davis, "Exploring future competitive advantage through sustainable supply chains," Int. J. Phys. Distrib. Logistics. Manag., vol. 37(9), pp. 763-774, 2007.

[20] T. Yildiz, and F. Yercan, "Environmental reporting of industrial and supply chain business processes within the context of sustainable 
development," 2011. Vol. 12(1). DOI: 10.3846/btp.2011.01

[21] Kumar, "Green Logistics For Sustainable Development: An Analytical Review," IOSRD International Journal of Business, 2015 Vol.1, p7-13.

[22] W. McDowall and M. Eames, "Forecasts, scenarios, visions, backcasts and roadmaps to the hydrogen economy: A review of the hydrogen futures literature," Energy Policy, vol. 34, no. 11, pp. 1236-1250, 2006, DOI: 10.1016/j.enpol.2005.12.006.

[23] J. Silva, G. M, Gomes, P. J. Sarkis, "The role of innovation in the implementation of green supply chain management practices," Bus. Strateg. Environ., vol. 28(5), no. 1-14, 2019.

[24] United Nations; Department of Economic and Social Affairs, "No Title," Department of Economic and Social Affairs, 2021. https://sdgs.un.org/goals.

[25] M. Piecyk, M.I., \& Alan, "Forecasting the carbon footprint of road freight transport in 2020," Int. J. Prod. Econ., vol. 128(1), pp. 31-42, 2010.

[26] D. Pujari, "Eco-innovation and new product development: Understanding the influences on market performance," Technovation, vol. 26, no. 1, pp. 76-85, 2006, DOI: 10.1016/j.technovation.2004.07.006.

[27] M. J. Franchetti, B. Elahi, and S. Ghose, Green Supply Chain, Logistics, and Transportation BT - Green and Lean Management. 2017.

[28] P. Trowbridge, "A case study of green supply chain management at advanced microdevices," Green. Supply Chain, pp. 307-322, 2006.

[29] R. Rostamzadeh, K. Govindan, A. Esmaeili, and M. Sabaghi, "Application of fuzzy VIKOR for evaluation of green supply chain management practices," Ecol. Indic., vol. 49, pp. 188-203, 2015, DOI: 10.1016/j.ecolind.2014.09.045.

[30] T. Sezer, S \& Abasiz, "The impact of logistic industry on economic growth: An application in OECD countries," Eurasian J. Soc. Sci., vol 5(1), pp. 11-23, 2017.

[31] A. Sharma, V.K, Chandna P \& Bhardwaj, "Green supply chain management related performance indicators in agro-industry: A review," J. Clean. Prod., vol. 141, no. 1194-1208, 2017.

[32] Q. Sun, J \& Zhu, "Organisational green supply chain management capability assessment: A hybrid group decision-making model application," IEEE Eng. Manag. Rev., vol. 2018, no. 46(1), pp. 117$127,2018$.

[33] P. Trowbridge, "A case study of green supply chain management at advanced microdevices," Green. Supply Chain, pp. 307-322, 2006.

[34] H. Hu \& C. W., Hsu. "Critical factors for implementing green supply chain management practice: an empirical study of electrical and electronics industries in Taiwan," Management Research Review, 2010, vol. 33(6), pp. 586-608.

[35] Teter, "The Future of Trucks: Implications for Energy and the Environment," Fr. Int. Energy Agency, pp. 1-66, 2017.

[36] Times of Oman, "Asyad formation to help Oman become top logistics hub - Times Of Oman," Times of Oman, 2017.

[37] Darko, "Drivers for implementing green building technologies: An international survey of experts," J. Clean. Prod., vol. 145(0), pp. 386394, 2017.

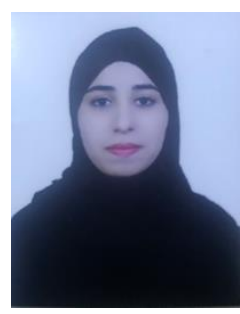

Asma Mohammed Al Jabri was born on the 7th of February 1999 in the Sultanate of Oman.

She is a bachelor's degree in Logistics and Transport Management from International Maritime College Oman, Suhar, Sultanate of Oman, 2021.

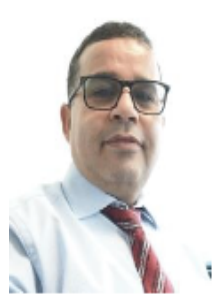

Mr Slimi is an English language lecturer at the international Maritime college Oman at the Foundation Department. Holder of BA in English Language and Literature from the faculty of Arts and Humanities Sousse/Tunisia, TESOL from ITTT, Masters' Degree in the Arts of Learning and Teaching from Roehampton University/UK and current PhD student at the Department of Psychology and Education Deusto University Spain. Mr Slimi is an editor at the European Journal of Education Sciences (EJES).

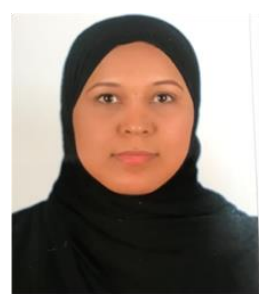

Mrs Al Yaqoobi is an assistant lecturer at the International Maritime College Oman in Logistics Management Department. Holder of a bachelor's degree in port, Shipping and Transport Management (Logistics Management) from International Maritime College Oman. Current Master student in International Operations and Supply Chain Management in Glasgow Caledonian University/Scotland.

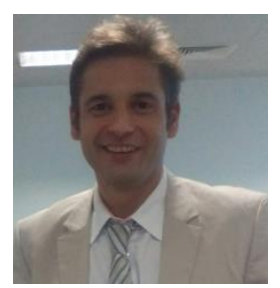

Mr Umut Mehmet is Lecturer of Logistics Management, International Maritime College Oman, Sohar, Oman. 